\title{
Cytokine profile in quadriceps muscles of patients with severe COPD
}

\author{
E Barreiro, ${ }^{1}$ A M W J Schols, ${ }^{2}$ M I Polkey, ${ }^{3}$ J B Galdiz, ${ }^{4}$ H R Gosker, ${ }^{2}$ E B Swallow, \\ $\mathrm{C}$ Coronell, ${ }^{1} \mathrm{~J}$ Gea, ${ }^{1}$ on behalf of the ENIGMA in COPD project
}

\section{See related editorial page 95}

- Supplementary data are published online only at http:// thorax.bmj.com/content/vol63/ issue2

\section{${ }^{1}$ Muscle and Respiratory}

System Research Unit (URMAR) and Respiratory Medicine Department, IMIM-Hospital del Mar, Centro de Investigación en Red de Enfermedades Respiratorias (CibeRes), Health and Experimental Sciences Department (CEXS), Pompeu Fabra University (UPF), Barcelona, Catalonia, Spain; ${ }^{2}$ Respiratory Medicine Department, Maastricht University Hospital, Maastricht, The Netherlands; ${ }^{3}$ Respiratory Medicine Department, Royal Brompton Hospital, Imperial College, London, UK;

${ }^{4}$ Pneumology Department and Research Unit, Cruces Hospital, Basque Country University, Barakaldo, Basque Country, Spain

Correspondence to: Dr E Barreiro, Muscle and Respiratory System Research Unit (URMAR), IMIM, C/Dr Aiguader, 88, Barcelona, E08003 Spain;

ebarreiro@imim.es

Received 15 January 2007 Accepted 23 August 2007 Published Online First 17 September 2007

\section{ABSTRACT}

Background: Systemic proinflammatory cytokines and oxidative stress have been described in association with peripheral muscle wasting and weakness of patients with severe chronic obstructive pulmonary disease (COPD), but their expression in skeletal muscle is unknown. The objectives of the present study were to determine muscle protein levels of selected cytokines in patients with COPD and to study their relationships with protein carbonylation as a marker of oxidative stress, quadriceps function and exercise capacity.

Methods: We conducted a cross sectional study in which 36 cytokines were detected using a human antibody array in quadriceps specimens obtained from 19 patients with severe COPD and seven healthy controls. Subsequently, selected cytokines (tumour necrosis factor (TNF) $\alpha$, TNF $\alpha$ receptors I and II, interleukin (IL) 6, interferon $\gamma$, transforming growth factor (TGF) $\beta$ and vascular endothelial growth factor (VEGF)), as well as protein carbonylation (oxidative stress index) were determined using an enzyme linked immunosorbent assay (ELISA) in all muscles.

Results: Compared with controls, the vastus lateralis of patients with COPD showed significantly lower protein ELISA levels of TNF $\alpha$, which positively correlated with their quadriceps function, TNF $\alpha$ receptor II and VEGF. Protein ELISA levels of IL6, interferon $\gamma$ and TGF $\beta$ did not differ between patients and controls. Quadriceps protein carbonylation was greater in patients and inversely correlated with quadriceps strength among them.

Conclusions: These findings do not support the presence of a proinflammatory environment within the quadriceps muscles of clinically and weight stable patients with severe COPD, despite evidence for increased oxidative stress and the presence of muscle weakness.

Muscle dysfunction, characterised by reduced muscle strength and endurance, is one of the most important systemic manifestations of advanced chronic obstructive pulmonary disease (COPD), leading to reduced exercise tolerance, quality of life and survival. ${ }^{1}$ Oxidative stress and systemic inflammation, among other factors, are proposed contributors to this process of muscle wasting and dysfunction, although their actual roles remain debatable. For instance, serum levels of the cytokine tumour necrosis factor (TNF) $\alpha$, its soluble receptors I and II and other inflammatory cytokines such as interleukin (IL) 6 and IL8 along with acute phase reactants were shown to be increased in patients with severe COPD and muscle wasting compared with patients with identical disease severity without weight loss. ${ }^{2-6}$
To date, only two studies ${ }^{7}$ have attempted to explore cytokine protein expression in the lower limb muscles of patients with severe COPD showing inconsistent results. Specifically, quadriceps of patients with severe COPD exhibited much greater levels of TNF $\alpha$ and inflammatory cell counts than controls in one study, ${ }^{7}$ while no immunohistochemical TNF $\alpha$ expression was detected in the muscles of patients or controls in the second study. ${ }^{8}$ Against this background, we hypothesised that patients with severe COPD and muscle weakness would exhibit increased levels of different cytokines, including TNF $\alpha$, in their limb muscles. To test this hypothesis, we first sought to explore the profile of multiple proinflammatory and anti-inflammatory cytokines using a human cytokine antibody array in the quadriceps of patients with severe COPD, with a wide spectrum of body composition and weight, and in those of healthy subjects. On the basis of both our antibody array results and of those from the current literature, ${ }^{2-6}$ we quantified protein levels of selected cytokines in all muscles using an enzyme linked immunosorbent assay (ELISA). We also explored muscle oxidative stress levels by measuring total protein carbonylation. Finally, we also assessed whether muscle cytokine levels and protein oxidation, as measured by ELISA, were associated with quadriceps strength and/or exercise capacity in the patients.

\section{METHODS \\ Subjects}

Nineteen male patients with stable severe COPD and seven healthy control individuals from four different European geographical areas were recruited on an outpatient basis. All individuals were Caucasian, and were simultaneously participating in the project of the European Network for Investigating the Global Mechanisms of Muscle Abnormalities (ENIGMA) in COPD, specifically designed to investigate the mechanisms involved in muscle dysfunction in COPD (www.pul.unimaas. $\mathrm{nl}$ /enigma/enigma.htm). A diagnosis of COPD was established on the basis of the guidelines of the Global Initiative for Chronic Obstructive Lung Disease. $^{9}$ The inclusion and exclusion criteria established in our study were identical in the four centres. All patients were exclusively receiving inhaled medication (long acting beta 2 agonists, anticholinergics and low dose inhaled corticosteroids). Patients receiving oral corticosteroid treatment were not included in the study. The sample size of both patient and control populations was calculated on the basis of formerly published 
human studies, where similar physiological and biological approaches were used. ${ }^{7}{ }^{10-12}$

\section{Study design}

This was a cross sectional study in which patients with COPD were compared with age matched healthy control subjects, designed in accordance with the ethical standards on human experimentation in our institutions. The ethics committees at IMIM-Hospital del Mar (Barcelona, Catalonia, Spain), Maastricht University Hospital (Maastricht, The Netherlands), Royal Brompton Hospital (London, UK) and Cruces Hospital (Barakaldo, Basque Country, Spain) approved all experiments. Informed written consent was obtained from all individuals (see the online supplement for additional information).

\section{Nutritional and functional assessment}

Nutritional evaluation included body mass index (BMI) and determination of the fat free mass index (FFMI) by bioelectrical impedance. ${ }^{13}$ Forced spirometry and determination of static lung volumes, carbon monoxide transfer and arterial blood gases were performed using standard procedures, and reference values by Quanjer and colleagues ${ }^{14}$ were used. Arterial blood gases were performed using standard procedures. Patients with COPD only performed a progressive incremental exercise test on a cycloergometer (Monark-Crescent 864; Varberg, Sweden). ${ }^{15}$ Quadriceps strength was evaluated in both patients and controls by isometric maximum voluntary contraction (MVC) and in response to magnetic stimulation of the dominant lower limb as formerly described, respectively ${ }^{16}{ }^{17}$ (see the online supplement for additional information).

\section{Biopsies}

Muscle samples from patients with COPD and controls were obtained from the quadriceps (vastus lateralis) by open muscle biopsy, as described previously, ${ }^{10}{ }^{11}$ at both IMIM-Hospital del
Mar and Cruces Hospital (11 patients and five controls), while the needle biopsy technique ${ }^{18}$ was used at Maastricht University and Royal Brompton Hospitals (eight patients and two controls). Samples were $20-30 \mathrm{mg}$ in size, on average. Muscle specimens were immediately frozen in liquid nitrogen and stored at $-80^{\circ} \mathrm{C}$ for further analysis or immersed in an alcoholformol bath for $2 \mathrm{~h}$ to be thereafter embedded in paraffin (see the online supplement for additional information).

\section{Muscle biopsy analyses}

All muscle biology analyses were conducted in the same laboratory (IMIM-Hospital del Mar).

\section{Human cytokine antibody arrays}

The expression of 36 cytokines was detected in the quadriceps muscles of both COPD patients and healthy controls using a specific human cytokine antibody array ${ }^{19}$ (Panomics, Inc. Redwood City, California, USA) following the manufacturer's instructions (see the online supplement for additional information).

\section{Cytokine ELISA}

After a careful analysis of the microarray cytokine profile in the quadriceps of both COPD patients and controls and on the basis of former studies, ${ }^{2-6}$ protein expression of the cytokines TNF $\alpha$, $\mathrm{TNF} \alpha$ receptors I and II, IL6, interferon $\gamma$, transforming growth factor (TGF) $\beta$ and vascular endothelial growth factor (VEGF) was quantified in all muscles using specific sandwich ELISA kits (Biosource Europe, Nivelles, Belgium) following the manufacturer's instructions for each cytokine (see the online supplement for additional information).

\section{Protein carbonyl ELISA}

Total levels of those highly reactive carbonyl groups in the protein side chains were detected by reaction (derivatisation) with 2,4-dinitrophenylhydrazine using the protein carbonyl

Table 1 Main characteristics and functional variables of the study subjects

\begin{tabular}{|c|c|c|c|}
\hline & $\begin{array}{l}\text { Control subjects }(\mathrm{n}=7) \\
\text { Mean (SD) }[95 \% \mathrm{Cl}]\end{array}$ & $\begin{array}{l}\text { COPD patients }(n=19) \\
\text { Mean (SD) }[95 \% \mathrm{Cl}]\end{array}$ & $\begin{array}{l}\text { Statistical data } \\
\text { Mean difference } \\
{[95 \% \mathrm{Cl}], \mathbf{p} \text { value }}\end{array}$ \\
\hline Age (y) & 63 (8) [52 to 74$]$ & 64 (8) [61 to 68$]$ & $-1[-12$ to +9$], p=0.742$ \\
\hline BMI $\left(\mathrm{kg} / \mathrm{m}^{2}\right)$ & 28 (1.7) [25.8 to 30$]$ & $22.5(5.2)$ [20 to 25$]$ & $+5.5[+2.5$ to +8.4$], p=0.001$ \\
\hline FFMI $\left(\mathrm{kg} / \mathrm{m}^{2}\right)$ & $19.1(1.2)$ [17.6 to 20.6] & $16(2.7)[14.6$ to 17.4$]$ & $+3.1[+1.3$ to +4.9$], p=0.002$ \\
\hline $\mathrm{FEV}_{1}(\%$ pred $)$ & 110 (18) [87 to 134$]$ & 33 (13) [27 to 40] & $+77[+54$ to +100$], p<0.0001$ \\
\hline FVC (\% pred) & $100(12)[85$ to 114$]$ & 69 (19) [60 to 78] & $+31[+16$ to +46$], p=0.001$ \\
\hline RV (\%) & 112 (1) [109 to 115$]$ & $202(50)$ [178 to 226$]$ & $-89[-113$ to -65$], p<0.0001$ \\
\hline TLC (\% pred) & 104 (4) [92 to 115] & $120(15)[113$ to 127$]$ & $-17[-26$ to -7$], p=0.002$ \\
\hline DLco (\% pred) & 93 (2) [88 to 98] & 47 (27) [32 to 61] & $+46[+32$ to +61$], p<0.0001$ \\
\hline KCO (\% pred) & 85 (5) [72 to 98$]$ & 57 (29) [41 to 72] & $+28[+12$ to +45$], p=0.002$ \\
\hline $\mathrm{PaO}_{2}(\mathrm{kPa})$ & NA & $9.2(1.4)$ [9.8 to 8.5$]$ & \\
\hline $\mathrm{PaCO}_{2}(\mathrm{kPa})$ & NA & $5.5(0.9)[5.9$ to 5.0$]$ & \\
\hline $\mathrm{Vo}_{2} \max (\% \mathrm{pred})$ & NA & 55 (7) [36 to 74$]$ & \\
\hline Wrmax (\% pred) & NA & 45 (8) [22 to 67] & \\
\hline OMVC (kg) & $40.4(6.2)[32.7$ to 48$]$ & 29.9 (8.9) [23.9 to 35.9$]$ & $+10.5[+1.9$ to +19$], p=0.02$ \\
\hline 0 twitch tension $(\mathrm{kg})$ & $10.2(2.4)$ [7.2 to 13.2$]$ & $8.5(2.7)[6.7$ to 10.2$]$ & $+1.7[-1.4$ to +4.8$], p=0.238$ \\
\hline Type I fibres (\%) & $43(10.6)$ [26 to 60$]$ & $29(7.4)[24$ to 33$]$ & $+14[-1$ to +30$], p=0.03$ \\
\hline Type II fibres (\%) & $57(10.6)[40$ to 74$]$ & $71(7.3)[66$ to 76$]$ & $-14[-30$ to +2$], p=0.03$ \\
\hline
\end{tabular}

Data are presented as mean (SD) and $[95 \% \mathrm{Cl}]$.

$\mathrm{BMI}$, body mass index; COPD, chronic obstructive pulmonary disease; $\mathrm{DLCo}$, carbon monoxide transfer; FEV ${ }_{1}$, forced expiratory volume in $1 \mathrm{~s}$; FFMI, fat free mass index; FVC, forced vital capacity; KCO, Krogh transfer factor; MVC, maximal velocity contraction; $\mathrm{NA}$, not available; $\mathrm{PaO}_{2}$, arterial oxygen partial pressure; $\mathrm{PaCO}_{2}$, arterial carbon dioxide partial pressure; pred, predicted; 0 , quadriceps; RV, residual volume; TLC, total lung capacity; $\mathrm{V}_{2}$ max, peak exercise oxygen uptake; Wrmax, maximal mechanical power output. 
Table 2 Microarray expression of the different cytokines in the quadriceps of the COPD patients with respect to the control subjects

\begin{tabular}{|c|c|c|c|}
\hline Cytokine & Control subjects & COPD patients & p Value \\
\hline CTLA (au) & $0.0281(0.0047)$ & $0.0192(0.0122)$ & 0.075 \\
\hline IL2 (au) & $0.0143(0.0001)$ & $0.0129(0.0067)$ & 0.120 \\
\hline IL6R (au) & $0.0125(0.0009)$ & $0.0143(0.0048)$ & 0.731 \\
\hline IL7 (au) & $0.0105(0.0002)$ & $0.0108(0.0036)$ & 0.629 \\
\hline IL15 (au) & $0.0204(0.0029)$ & $0.0205(0.0131)$ & 0.891 \\
\hline MIP-1 $\alpha(a u)$ & $0.0127(0.0001)$ & $0.0095(0.0025)$ & 0.005 \\
\hline TGF $\beta$ (au) & $0.0078(0.0002)$ & $0.0044(0.0012)$ & 0.005 \\
\hline VCAMP-1 (au) & $0.0142(0.0029)$ & $0.0128(0.0043)$ & 0.075 \\
\hline VEGF (au) & $0.0102(0.0058)$ & $0.0081(0.0051)$ & 0.036 \\
\hline Apol/Fas (au) & $0.0193(0.0025)$ & $0.0159(0.0098)$ & 0.120 \\
\hline GM-CSF (au) & $0.0149(0.0006)$ & $0.0155(0.0053)$ & 0.235 \\
\hline IL3 (au) & $0.0137(0.0010)$ & $0.0120(0.0030)$ & 0.005 \\
\hline IL6 (au) & $0.0088(0.0051)$ & $0.0120(0.0050)$ & 0.945 \\
\hline IL10 (au) & $0.0110(0.0030)$ & $0.0111(0.0022)$ & 0.331 \\
\hline IL17 (au) & $0.0121(0.0012)$ & $0.0114(0.0052)$ & 0.019 \\
\hline MIP-1 $\beta$ (au) & $0.0119(0.0021)$ & $0.0109(0.0028)$ & 0.044 \\
\hline MIP-4 (au) & $0.0193(0.0044)$ & $0.0184(0.0072)$ & 0.183 \\
\hline IFN $\gamma(\mathrm{au})$ & $0.0096(0.0017)$ & $0.0045(0.0056)$ & 0.036 \\
\hline RANTES (au) & $0.0144(0.0033)$ & $0.0106(0.0071)$ & 0.160 \\
\hline Leptin (au) & $0.0208(0.0022)$ & $0.0195(0.0096)$ & 0.235 \\
\hline IL5 (au) & $0.0037(0.0067)$ & $0.0040(0.0073)$ & 0.367 \\
\hline IL12 (au) & $0.0414(0.0102)$ & $0.0393(0.0175)$ & 0.783 \\
\hline MIP-5 (au) & $0.0118(0.0023)$ & $0.0140(0.0049)$ & 0.367 \\
\hline TNF $\alpha$ (au) & $0.0189(0.0019)$ & $0.0113(0.0055)$ & $<0.0001$ \\
\hline TNF $\alpha$ R I (au) & $0.0164(0.0004)$ & $0.0184(0.0051)$ & 0.891 \\
\hline TNF $\alpha$ R II (au) & $0.0189(0.0022)$ & $0.0236(0.0092)$ & 0.075 \\
\hline IL1 $\alpha$ (au) & $0.0015(0.0015)$ & $0.0030(0.0028)$ & 0.265 \\
\hline IL1 $\beta$ (au) & $0.0089(0.0036)$ & $0.0086(0.0051)$ & 0.103 \\
\hline $\operatorname{IL} 1 \mathrm{R} \alpha(\mathrm{au})$ & $0.0137(0.0062)$ & $0.0166(0.0049)$ & 0.731 \\
\hline IL4 (au) & $0.0222(0.0051)$ & $0.0226(0.0098)$ & 0.999 \\
\hline IL8 (au) & $0.0129(0.0024)$ & $0.0134(0.0016)$ & 0.139 \\
\hline Eotaxin (au) & $0.0208(0.0020)$ & $0.0202(0.0064)$ & 0.075 \\
\hline EGF (au) & $0.0231(0.0005)$ & $0.0209(0.0048)$ & 0.019 \\
\hline MMP3 (au) & $0.0166(0.0014)$ & $0.0228(0.0101)$ & 0.120 \\
\hline ICAMP-1 (au) & $0.0124(0.0039)$ & $0.0135(0.0059)$ & 0.731 \\
\hline IP-10 (au) & $0.0122(0.0051)$ & $0.0166(0.0078)$ & 0.367 \\
\hline
\end{tabular}

\footnotetext{
Data are presented as median and (interquartile range).

$\mathrm{au}$, arbitrary units; COPD, chronic obstructive pulmonary disease; CTLA, cytotoxic T lymphocyte antigen; EGF, epidermal growth factor; GM-CSF, granulocyte-macrophage-colony stimulating factor; ICAM, intercellular adhesion molecule; IFN, interferon; IL, interleukin; IP-10, interferon $\gamma$ inducible protein 10; MIP, macrophage inflammatory protein; MMP, matrix metalloproteinases; $R$, receptor; RANTES, regulated upon activation normal T cell expressed and secreted; TGF, transforming growth factor; TNF, tumour necrosis factor; VCAMP; vascular cell adhesion molecule; VEGF, vascular endothelial growth factor.
}

enzyme immunoassay kit (Zenith Technologies Corp. Ltd, Dunedin, New Zealand) following the manufacturer's instructions (see the online supplement for additional information).

\section{Immunohistochemistry}

Muscle morphometry in both patients and controls was assessed as previously described. ${ }^{10}{ }^{12}$ Monoclonal anti-MyHC-I (clone MHC; Biogenesis Inc., UK, 1/20 dilution) and monoclonal anti-MyHC-II (clone MY-32; Sigma, St Louis, Missouri, USA, 1/100 dilution) antibodies were used to identify type I and type II muscle fibres, respectively. At least 100 fibres were counted in each specimen (see the online supplement for additional information).

\section{Statistical analysis}

Data are presented as mean (SD) with $95 \%$ confidence intervals (CI) for parametric data (table 1) and as median (interquartile range) for non-parametric data (table 2). The unpaired t test or the Mann-Whitney non-parametric test was used for comparisons between controls and COPD patients. While $95 \%$ $\mathrm{CI}$, mean differences and $\mathrm{p}$ values were indicated for the parametric $t$ test, only exact $p$ values were noted for the MannWhitney non-parametric test. Spearman's correlation coefficient was used to assess relationships among different variables within all COPD patients. The sample size was based on assumptions of $80 \%$ power to detect an improvement of more than $20 \%$ in measured outcomes at a level of significance of $p \leqslant 0.05$.

\section{RESULTS}

\section{Characteristics of the study subjects}

Table 1 shows the main characteristics of the study subjects. As expected, no significant differences were found in age between controls and patients with COPD, and pulmonary function testing confirmed the presence of advanced disease among the patient group. BMI and FFMI were significantly lower in patients compared with controls. Muscle strength, as evaluated by quadriceps MVC, was significantly reduced in patients 
Figure 1 (A) Mean (SD) values for tumour necrosis factor (TNF) $\alpha$, as measured by ELISA, were significantly lower in the quadriceps of patients with severe chronic obstructive pulmonary disease (COPD) compared with control (CTL) muscles $(21.9(15.2) \mathrm{pg} / \mathrm{ml}(95 \% \mathrm{Cl}$ 14.0 to 29.7$)$ vs $37.0(16.5) \mathrm{pg} / \mathrm{ml}(95 \% \mathrm{Cl}$ 16.5 to 57.5$)$, mean difference +15.1 $(95 \% \mathrm{Cl}-4.9$ to +35.2$))$. (B) Mean (SD) values for TNF $\alpha$ receptor II, as measured by ELISA, were significantly lower in the muscles of the patients with COPD compared with controls $(0.5(0.3) \mathrm{pg} / \mathrm{ml}$ (95\% Cl 0.3 to 0.74$)$ vs $0.9(0.1) \mathrm{pg} / \mathrm{ml}$ $(95 \% \mathrm{Cl} 0.7$ to 1.1$)$, mean difference +0.4 $(95 \% \mathrm{Cl}+0.1$ to +0.6$))$. (C) Among all COPD patients, muscle TNF $\alpha$ levels significantly and positively correlated with both maximum voluntary contraction (MVC) (left) and twitch force of the quadriceps (0) (right). Note that only 11 and 12 COPD patients are depicted in the corresponding graphs, respectively, as these physiological measurements could not be obtained in all patients or gave error values in a few.
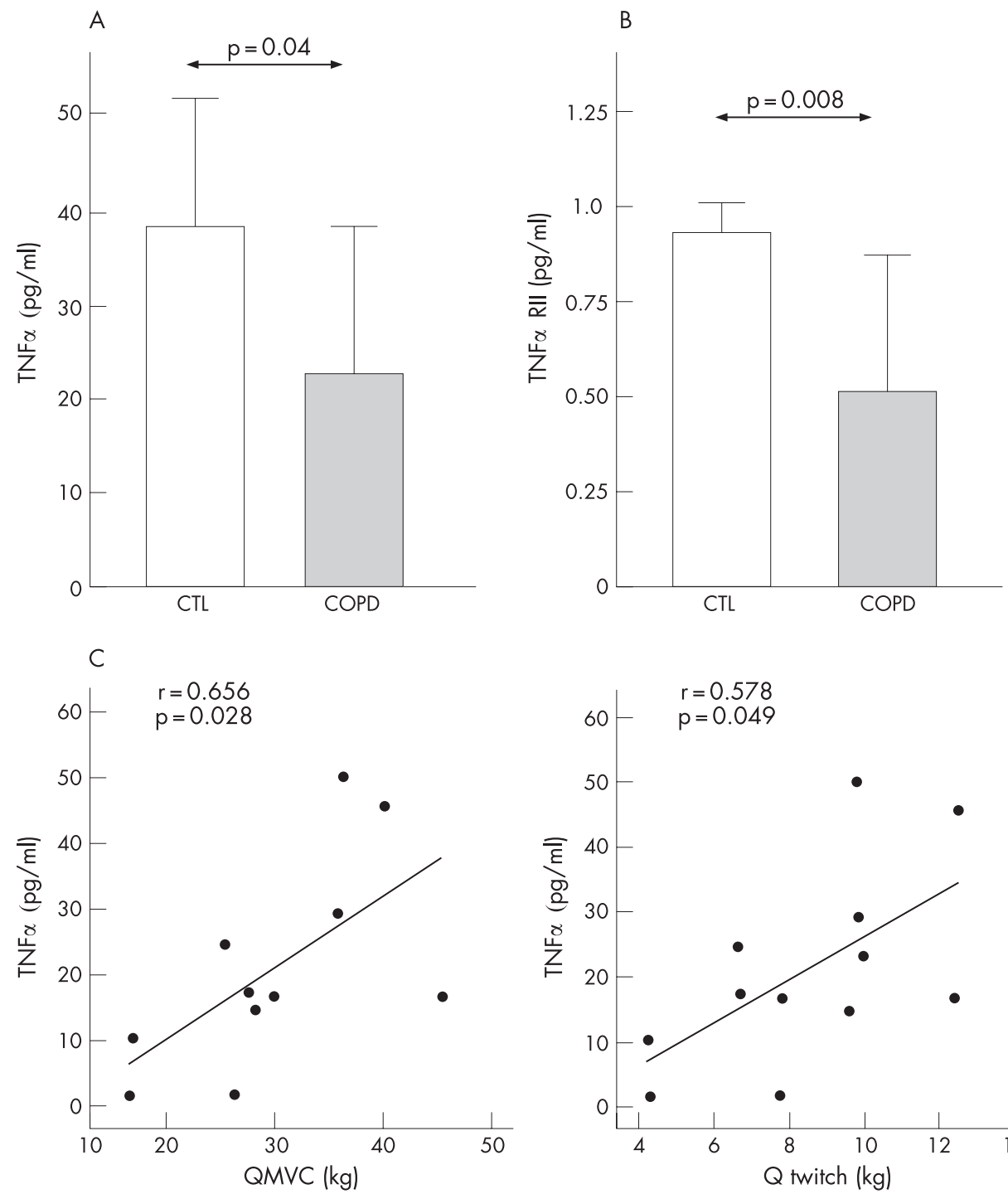

compared with controls (mean (SD) MVC 40.4 (6.2) kg vs 29.9 (8.9); $p=0.02$ ), although this did not achieve significance for twitch tension. The proportions of type I fibres were significantly lower while those of type II fibres were higher in the quadriceps of patients with COPD compared with controls $(\mathrm{p}=0.03)$.

\section{Microarray expression of the different cytokines}

Table 2 shows the cytokine levels (optical densities expressed as arbitrary units) detected using the specific human cytokine antibody arrays (see the online supplement for additional information).

\section{Muscle specific protein expression (ELISA measurements)} Expression of TNF $\alpha$ and TNF $\alpha$ receptors I and II

As shown in fig $1 \mathrm{~A}$, protein expression (ELISA measurements) of the cytokine TNF $\alpha$ was lower in the muscles of the patients with COPD compared with controls. No significant differences were observed in the levels of TNF $\alpha$ receptor I in the muscles of the COPD patients compared with those in controls $(0.20$ (0.051) pg/ml (95\% CI 0.17 to 0.23$)$ vs $0.21(0.04) \mathrm{pg} / \mathrm{ml}$ (95\% CI 0.157 to 0.256$)$, mean difference +0.003 (95\% CI -0.047 to $+0.054)$ ). However, ELISA levels of the TNF $\alpha$ receptor II were significantly reduced in the quadriceps of patients with COPD compared with controls (fig 1B). When the COPD patients were analysed as a group, muscle TNF $\alpha$ ELISA levels significantly and positively correlated with both MVC and the involuntary twitch force of the quadriceps (fig 1C). Moreover, TNF $\alpha$ levels were also positively correlated with those of the TNF $\alpha$ receptor II $(r=0.932, p<0.001)$. No other relationships were found between TNF $\alpha$ or TNF $\alpha$ receptors I and II and lung function, exercise tolerance parameters or fibre type distribution among all patients with COPD.

\section{Expression of IL6, Interferon $\gamma$ and TGF $\beta$}

Mean (SD) values for IL6, as measured by ELISA, did not differ between patients with COPD and controls (18.9 (3.1) pg/ml (95\% CI 17.4 to 20.4 ) vs 19.5 (2.2) pg/ml (95\% CI 16.8 to 22.2 ), mean difference $+0.6(95 \% \mathrm{CI}-2.1$ to +3.3$))$. Likewise, muscle protein levels of interferon $\gamma$ did not show any significant difference between patients and controls (10.4 (1.7) IU/ml (95\% CI 9.3 to 11.5$)$ vs 11.9 (2.9) IU/ml (95\% CI 8.2 to 15.6), mean difference $+1.5(95 \%$ CI -2.1 to +5.1$)$ ). Muscle levels of the cytokine TGF $\beta$ were also similar between patients with COPD and controls (23.2 (6.9) pg/ml (95\% CI 19.9 to 26.5) vs 23.0 (2.5) $\mathrm{pg} / \mathrm{ml}$ (95\% CI 19.9 to 26.1$)$, mean difference $-0.1(95 \%$ CI -4.2 to +3.9$))$. 


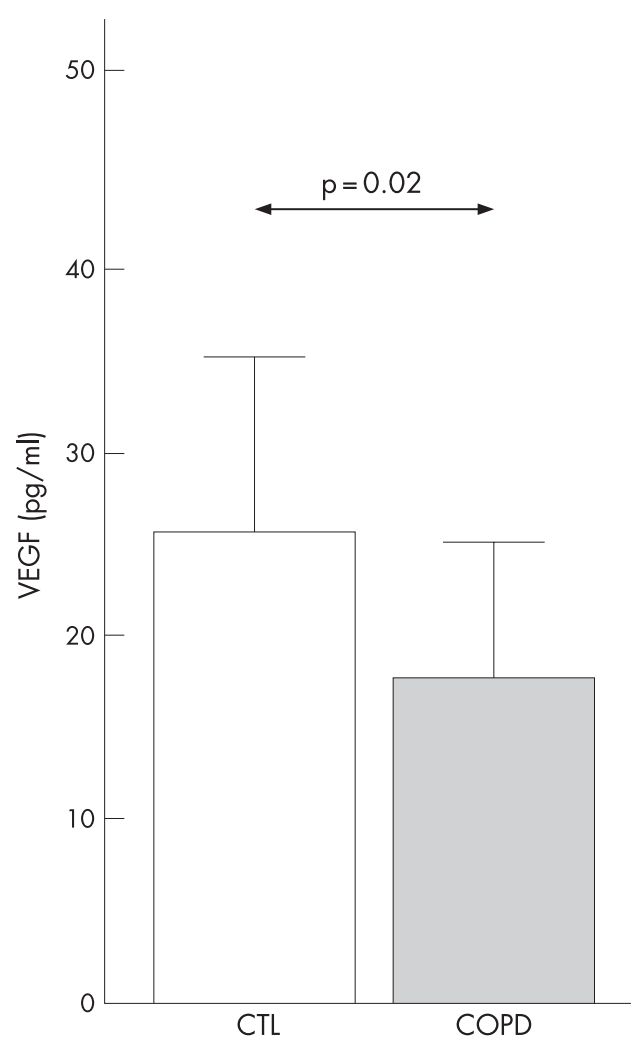

Figure 2 Mean (SD) values for vascular endothelial growth factor (VEGF), as measured by ELISA, were significantly lower in the muscles of patients with chronic obstructive pulmonary disease (COPD) compared with control (CTL) muscles $(16.8(6.9) \mathrm{pg} / \mathrm{ml}(95 \% \mathrm{Cl} 13.4$ to 20.1) vs 25.2 (9.7) pg/ml (95\% Cl 9.7 to 40.7), mean difference +8.5 $(95 \% \mathrm{Cl}-6.3$ to +23.2$))$.

\section{Expression of VEGF}

Protein levels of the cytokine VEGF (ELISA measurements) were significantly reduced in the quadriceps of COPD patients compared with control muscles (fig 2). No relationships were found between muscle levels of VEGF, lung or muscle functions, exercise tolerance parameters or fibre type distribution among all patients with COPD (see the online supplement for additional information).

\section{Muscle protein carbonylation (ELISA measurements)}

Muscle protein carbonylation levels were significantly higher in the quadriceps of COPD patients than in controls (fig 3A). When considering all COPD patients as a group, muscle protein carbonylation levels were significantly and negatively correlated with both MVC and the involuntary twitch force of the quadriceps (fig 3B), as well as with muscle levels of TGF $\beta$ (fig 3C). There was a trend towards an inverse correlation between TNF $\alpha$ levels and the magnitude of protein carbonylation in the muscles of all patients with COPD $(r=-0.451$, $p=0.08$ ). No other relationships were found between muscle protein carbonylation, lung function, exercise tolerance parameters or fibre type distribution among all COPD patients.

\section{DISCUSSION}

The main findings in this study were obtained as a result of a prospective exploratory approach using antibody microarrays followed by specific quantification of selected cytokines in the muscles. Hence, in patients with COPD compared with control subjects, we found that: (1) BMI, FFMI, quadriceps force and type I fibres were significantly reduced, (2) muscle TNF $\alpha$ levels were significantly reduced and positively correlated with quadriceps strength, (3) muscle levels of the TNF $\alpha$ receptor II were also significantly reduced and were related to those of TNF $\alpha$, (4) muscle levels of the cytokine VEGF were lower and (5) muscle protein oxidation, as measured by total protein carbonylation, was significantly increased and negatively correlated with quadriceps muscle strength among all patients.

\section{Study limitations}

The main limitations of our study are related to the small size of the muscle specimens and the relatively small number of both patients and controls recruited. As the study involved the use of relatively "invasive" procedures and many different tests were performed in most of the study subjects, we were compelled to obtain rather small muscle specimens. In addition, the volunteer healthy control individuals were recruited on an outpatient basis and had not been hospitalised for any reason in the previous months before study entry as opposed to former studies where subjects underwent surgical procedures. Moreover, very restrictive inclusion and exclusion criteria were used to carefully select the study population. Another limitation encountered in our study was directly related to the methodology. As we chose quite a comprehensive exploratory approach to the study of levels of several cytokines in the quadriceps of our population, we were compelled to use those types of laboratory techniques that require relatively little amounts of sample because of their high sensitivity. It should also be mentioned that the results obtained using the antibody microarray on the one hand, and the ELISA on the other, showed some discrepancies with regard to protein expression of the cytokines interferon $\gamma$ and TGF $\beta$. The fact that the former is basically a qualitative exploratory technique whereas the latter is an accurate method to specifically quantify protein levels probably account for such discrepancies. Moreover, the ELISA results were confirmed and verified by repetition of some of the experiments as well as by the use of triplicates in all cases.

\section{Quadriceps muscle structure and function}

Quadriceps muscle dysfunction has been well established in the past decade ${ }^{16}{ }^{20-22}$ Among several mechanisms, decreased proportions of type I fibres have been observed in association with quadriceps muscle dysfunction of patients with COPD. ${ }^{22}$ In the present study, compared with controls, both quadriceps strength and proportions of type I fibres were reduced in patients. These findings are indeed consistent with the current literature ${ }^{20-24}$ and suggest that our cohort was typical of patients with advanced disease.

\section{Cytokines in the vastus lateralis}

TNF $\alpha$ is a pleotropic cytokine that has long been considered to be involved in the muscle loss of patients with chronic wasting conditions, such as cancer and COPD. In fact, it has been shown that systemic inflammatory cytokines such as TNF $\alpha$, its soluble receptors I and II, IL6 and IL8, along with acute phase reactants, are increased in the blood of patients with severe COPD and muscle wasting compared with healthy controls. ${ }^{2-6}{ }^{25}$ In line with this, other studies have also demonstrated an increase in various blood inflammatory cells, which might be involved in the release of systemic inflammatory cytokines in COPD patients. ${ }^{626}{ }^{27}$ Furthermore, systemic TNF $\alpha$ has been proposed to exert catabolic actions in muscles as well as to induce contractile dysfunction in chronic inflammatory conditions, 
Figure 3 (A) Mean (SD) values of total protein carbonylation, as measured by ELISA, were higher in the quadriceps of patients with chronic obstructive pulmonary disease (COPD) compared with controls (CTL) $(0.83(0.22) \mathrm{pg} / \mathrm{ml}$ (95\% Cl 0.69 to 0.96$)$ vs $0.46(0.32) \mathrm{pg} /$ $\mathrm{ml}(95 \% \mathrm{Cl} 0.06$ to 0.86$)$, mean difference $-0.37(95 \% \mathrm{Cl}-0.76$ to +0.02$))$. (B) Among all COPD patients, muscle protein oxidation (protein carbonylation) significantly and negatively correlated with both maximum voluntary contraction (MVC) (left) and twitch force of the quadriceps (0) (right). Note that only 10 and 11 COPD patients are depicted in the corresponding graphs, respectively, as these physiological measurements could not be obtained in all patients, and one patient showed error values in protein carbonylation levels. (C) Among all COPD patients, quadriceps protein carbonylation levels significantly and negatively correlated with those of transforming growth factor (TGF) $\beta$. Note that only 14 patients are depicted in the graph, as quantification of either TGF $\beta$ or protein carbonylation levels were either not available or gave error values in a few patients.
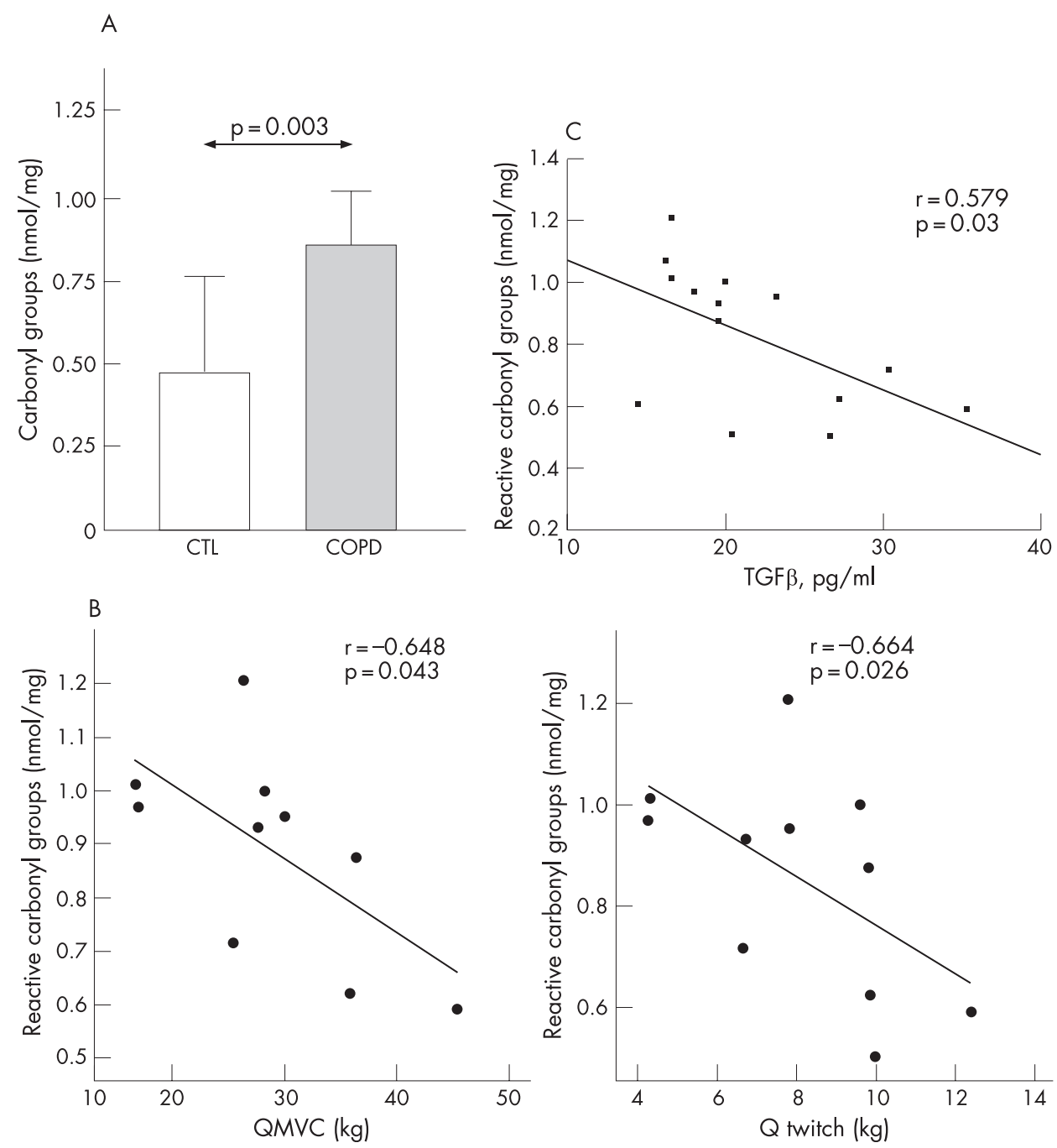

including COPD.$^{28}$ In keeping with this, TNF $\alpha$ has been shown to inhibit myogenesis through several mechanisms in in-vitro studies. ${ }^{29}{ }^{30}$ However, the argument has been put forward that $\mathrm{TNF} \alpha$ may also promote skeletal muscle regeneration and remodelling, as demonstrated in animal and in-vitro studies. ${ }^{31}{ }^{32}$

In the present study, refuting our initial hypothesis, ELISA protein levels of both TNF $\alpha$ and its receptor II were reduced by approximately $45 \%$ in the quadriceps of our COPD patients compared with levels detected in controls. Furthermore, among all patients, significant positive correlations were found between quadriceps force and muscle TNF $\alpha$ levels, suggesting that this cytokine is somehow involved in the muscle contractile performance of these patients. Recent observations from some of us, ${ }^{33}{ }^{34}$ however, have shown increased mRNA and protein levels of TNF $\alpha$ in the diaphragms and external intercostals of patients with COPD compared with controls. This is also consistent with former studies where expression of TNF $\alpha$, IL6, IL1 $\beta$ and interferon $\gamma$ was increased in the diaphragms of rats exposed to resistive breathing ${ }^{35}$ as well as in the myocardium of rodents subjected to mechanical loading. ${ }^{36}$ Collectively, these results raise the hypothesis that the expression of proinflammatory cytokines within muscle fibres is likely to be differentially regulated on the basis of the activity of each muscle.

In line with our findings, a recent study has also shown the absence of immunohistochemical TNF $\alpha$ expression as well as very low levels of neutrophils in the quadriceps of patients with severe COPD with and without hypoxaemia either at rest or after local exercise. ${ }^{8}$ Montes de Oca et al, ${ }^{7}$ however, have recently shown a large increase in $\mathrm{TNF} \alpha$ levels and other inflammatory parameters, as well as in leucocyte counts in the quadriceps of patients with severe COPD with normal and low BMI. To explain the discrepancy, we note that patients in our study were more severely malnourished, that body composition, as assessed by the FFMI, was not explored in the study of Montes de Oca et al and that inflammatory cell counts were only performed in four patients, ${ }^{7}$ and not in the whole population of their study. Clearly, the design of future studies is required in order to unravel these important questions. We suggest that examining levels of inflammatory cells, which we now predict are probably very low in the limb muscles of our patients, would be worthwhile as well as prestratification of COPD patients by muscle atrophy profile. Data thus far suggest an absence of inflammatory cells in the quadriceps of patients with severe COPD compared with control muscles. ${ }^{24}$ On the other hand, the possible contribution of increased circulating blood cytokines to muscle dysfunction in COPD patients cannot be ruled out in our study as no blood analyses were performed. We believe this factor should also be taken into consideration in future studies.

Another factor that might be implicated in the regulation of the expression of muscle cytokines in severe COPD is hypoxia. We do not believe, however, that chronic hypoxia has taken 
place in the limb muscles of our COPD patients because their hypoxaemia was relatively mild (mean $\mathrm{PaO}_{2} 9.2 \mathrm{kPa}$ ) and we saw no correlation between $\mathrm{TNF} \alpha$ and $\mathrm{PaO}_{2}$. On the other hand, quadriceps muscle vascular remodelling and angiogenesis have been suggested to be reduced in COPD. ${ }^{23} 3738$ Hence, the decreased VEGF protein expression observed in the quadriceps of our severe COPD patients could partially account for the proposed reduced remodelling of these muscles.

\section{Muscle oxidative stress and its relationships with muscle cytokines}

We and other investigators ${ }^{6}$ 10-12 $^{39-43}$ have already shown that protein oxidation is increased in the muscles of patients with COPD. Indeed, oxidative stress has widely been proposed as one of the most important mechanisms involved in the aetiology of peripheral muscle dysfunction in COPD. In the current study, we confirmed once more that lower limb muscle proteins undergo severe oxidation. Moreover, two novel findings are being reported: among all COPD patients, protein carbonylation was negatively associated with both quadriceps muscle function and TGF $\beta$ levels in these muscles. These results support the concept that oxidation of target muscle proteins likely to be involved in muscle force generation contributes to peripheral muscle dysfunction in severe COPD. In line with this, we have recently demonstrated ${ }^{11}$ that creatine kinase is more oxidised in the quadriceps of patients with severe COPD and that the activity of such an enzyme was inversely related to its levels of oxidation.

In our study, increased protein oxidation was inversely related to cytokine expression in the quadriceps of patients with very severe COPD and relative muscle loss. The molecular sources of oxidants in the quadriceps of COPD patients remain to be elucidated. On the basis of studies conducted on models of disuse and atrophy, it could be speculated that xanthine oxidase, reactive iron and probably NADPH oxidase would produce reactive oxygen species that may further react with nitric oxide to form the highly reactive species peroxynitrite, which, in turn, would lead to the formation of 3-nitrotyrosine. On the other hand, growing evidence shows that nitric oxide may also inhibit cytokine production in skeletal muscles. ${ }^{44}$ Therefore, it would be possible to conclude that excessive reactive nitrogen species production, as shown to occur in the quadriceps of patients with COPD, ${ }^{10}$ might partly account for the reduced cytokine protein levels encountered in the current study. Clearly, the design of future studies targeted to explore the specific roles of oxidative stress, molecular sources of reactive oxygen species and cytokine expression as well as the potential links among them in the COPD associated peripheral muscle dysfunction is of paramount importance.

\section{CONCLUSIONS}

Our findings do not support the presence of a proinflammatory environment within the quadriceps muscles of patients with severe COPD, despite evidence for increased oxidative stress and the presence of muscle weakness.

\footnotetext{
Acknowledgements: This study was supported by the European Network for Investigating the Global Mechanisms of Muscle Abnormalities in patients with Chronic Obstructive Pulmonary Disease (ENIGMA in COPD) (OLK6-CT-2002-02285) (European Union), and both RESPIRA (RTIC C03/11) and FIS 05/2486 (Spain). Dr Esther Barreiro is a scholar of the Fondo de Investigación Sanitaria (FIS) of the Spanish Health Ministry. We gratefully acknowledge Mr Francesc Sanchez and Ms Sandra Mas for their technical assistance in the laboratory, Dr Rafael Marcos for his technical assistance with the statistical analyses and Mr Roger Marshall for his editing aid.
}

Competing interests: None.

Ethics approval: yes.

\section{REFERENCES}

1. Swallow EB, Reyes D, Hopkinson NS, et al. Quadriceps strength predicts mortality in patients with moderate to severe chronic obstructive pulmonary disease. Thorax 2007:62:115-20.

2. Di Francia M, Barbier D, Mege JL, et al. Tumor necrosis factor-alpha levels and weight loss in chronic obstructive pulmonary disease. Am J Respir Crit Care Med 1994;150:1453-5.

3. Schols AM, Buurman WA, Staal van den Brekel AJ, et al. Evidence for a relation between metabolic derangements and increased levels of inflammatory mediators in a subgroup of patients with chronic obstructive pulmonary disease. Thorax 1996;51:819-24.

4. Takabatake N, Nakamura $\mathrm{H}$, Abe $\mathrm{S}$, et al. The relationship between chronic hypoxemia and activation of the tumor necrosis factor-alpha system in patients with chronic obstructive pulmonary disease. Am J Respir Crit Care Med 2000;161:1179_ 84.

5. Takabatake N, Nakamura $\mathrm{H}$, Abe $\mathrm{S}$, et al. Circulating leptin in patients with chronic obstructive pulmonary disease. Am J Respir Crit Care Med 1999;159:1215-19.

6. Van Helvoort HA, Heijdra YF, Thijs HM, et al. Exercise-induced systemic effects in muscle-wasted patients with COPD. Med Sci Sports Exerc 2006;38:1543-52.

7. Montes de $\mathbf{O c a} \mathbf{M}$, Torres SH, De Sanctis J, et al. Skeletal muscle inflammation and nitric oxide in patients with COPD. Eur Respir J 2005;26:390-7.

8. Koechlin C, Maltais F, Saey D, et al. Hypoxaemia enhances peripheral muscle oxidative stress in chronic obstructive pulmonary disease. Thorax 2005;60:834-41.

9. Fabbri LM, Hurd SS. Global strategy for the diagnosis, management and prevention of COPD: 2003 update. Eur Respir J 2003;22:1-2.

10. Barreiro E, Gea J, Corominas JM, et al. Nitric oxide synthases and protein oxidation in the quadriceps femoris of COPD patients. Am J Respir Cell Mol Biol 2003:29:7718

11. Barreiro E, Gea J, Matar G, et al. Expression and carbonylation of creatine kinase in the quadriceps femoris muscles of patients with chronic obstructive pulmonary disease. Am J Respir Cell Mol Biol 2005;33:636-42.

12. Barreiro $\mathbf{E}$, de la Puente $B$, Minguella, et al. Oxidative stress and respiratory muscle dysfunction in severe chronic obstructive pulmonary disease. Am J Respir Crit Care Med 2005;171:1116-24.

13. Steiner MC, Barton RL, Singh SJ, et al. Bedside methods versus dual energy X-ray absorptiometry for body composition measurement in COPD. Eur Respir $J$ 2002;19:626-31.

14. Quanjer PH, Tammeling GJ, Cotes JE, et al. Lung volumes and forced ventilatory flows. Report Working Party Standardization of Lung Function Tests, European Community for Steel and Coal. Official Statement of the European Respiratory Society. Eur Respir J Supp/ 1993;16:5-40.

15. Jones NL, Makrides L, Hitchcock J, et al. Normal standards for an incremental progressive cycle ergometer test. Am Rev Respir Dis 1985;131:700-8.

16. Coronell C, Orozco-Levi M, Mendez R, et al. Relevance of assessing quadriceps endurance in patients with COPD. Eur Respir J 2004;24:129-36.

17. Hopkinson NS, Nickol AH, Payne J, et al. Angiotensin converting enzyme genotype and strength in chronic obstructive pulmonary disease. Am J Respir Crit Care Med 2004:170:395-9.

18. Bergstrom L. Muscle electrolytes in man. Determination by neutron activation analysis on needle biopsy specimens. A study on normal subjects, kidney patients, and patients with chronic diarrhea. Scand J Clin Lab Invest 1962;68:1-110.

19. Huang RP. Detection of multiple proteins in an antibody-based protein microarray system. J Immunol Methods 2001:255:1-13.

20. Gosselink R, Troosters T, Decramer M. Peripheral muscle weakness contributes to exercise limitation in COPD. Am J Respir Crit Care Med 1996;153:976-80.

21. Bernard S, LeBlanc P, Whittom F, et al. Peripheral muscle weakness in patients with chronic obstructive pulmonary disease. Am J Respir Crit Care Med 1998;158:62934.

22. Skeletal muscle dysfunction in chronic obstructive pulmonary disease. A statement of the American Thoracic Society and European Respiratory Society. Am J Respir Crit Care Med 1999;159:s1-40.

23. Whittom F, Jobin J, Simard PM, et al. Histochemical and morphological characteristics of the vastus lateralis muscle in patients with chronic obstructive pulmonary disease. Med Sci Sports Exerc 1998;30:1467-74.

24. Gosker HR, Kubat B, Schaart G, et al. Myopathological features in skeletal muscle of patients with chronic obstructive pulmonary disease. Eur Respir J 2003;22:280-5.

25. Rabinovich RA, Figueras M, Ardite E, et al. Increased tumour necrosis factor-alpha plasma levels during moderate-intensity exercise in COPD patients. Eur Respir J 2003;21:789-94.

26. Noguera A, Batle $S$, Miralles C, et al. Enhanced neutrophil response in chronic obstructive pulmonary disease. Thorax 2001;56:432-7.

27. Sauleda J, Garcia-Palmer FJ, Gonzalez G, et al. The activity of cytochrome oxidase is increased in circulating lymphocytes of patients with chronic obstructive pulmonary disease, asthma, and chronic arthritis. Am J Respir Crit Care Med 2000:161:32-5.

28. Reid MB, Li YP. Cytokines and oxidative signalling in skeletal muscle. Acta Physiol Scand 2001;171:225-32.

29. Langen RC, Schols AM, Kelders MC, et al. Tumor necrosis factor-alpha inhibits myogenesis through redox-dependent and -independent pathways. Am J Physiol Cell Physiol 2002;283:C714-21.

30. Langen RC, Van Der Velden JL, Schols AM, et al. Tumor necrosis factor-alpha inhibits myogenic differentiation through MyoD protein destabilization. FASEB J 2004;18:227-37. 
31. Li YP. TNF-alpha is a mitogen in skeletal muscle. Am J Physiol Cell Physiol 2003;285:C370-6.

32. Warren GL, Hulderman T, Jensen N, et al. Physiological role of tumor necrosis factor alpha in traumatic muscle injury. FASEB J 2002:16:1630-2.

33. Casadevall C, Barreiro E, Orozco-Levi M, et al. Local expression of tumor necrosis factor-alpha: Is it the baddy or the goody in the story of respiratory muscle adaptation occurring in COPD? Proc Am Thorac Soc 2006:3:A26.

34. Casadevall C, Coronell C, Ramirez-Sarmiento AL, et al. Upregulation of proinflammatory cytokines in the intercostal muscles of COPD patients. Eur Respir $\mathrm{J}$ 2007:30:701-7.

35. Vassilakopoulos T, Divangahi M, Rallis G, et al. Differential cytokine gene expression in the diaphragm in response to strenuous resistive breathing. Am J Respir Crit Care Med 2004;170:154-61.

36. Baumgarten G, Knuefermann P, Kalra D, et al. Load-dependent and -independent regulation of proinflammatory cytokine and cytokine receptor gene expression in the adult mammalian heart. Circulation 2002;105:2192-7.

37. Jobin J, Maltais F, Doyon JF, et al. Chronic obstructive pulmonary disease: capillarity and fiber-type characteristics of skeletal muscle. J Cardiopulm Rehabil 1998:18: $432-7$.
38. Saey D, Michaud A, Couillard A, et al. Contractile fatigue, muscle morphometry, and blood lactate in chronic obstructive pulmonary disease. Am J Respir Crit Care Med 2005; 171:1109-15.

39. Engelen MP, Schols AM, Does JD, et al. Altered glutamate metabolism is associated with reduced muscle glutathione levels in patients with emphysema. Am J Respir Crit Care Med 2000;161:98-103.

40. Rabinovich R, Ardite E, Troosters T, et al. Reduced muscle redox capacity after endurance training in patients with chronic obstructive pulmonary disease. Am J Respir Crit Care Med 2001;164:1114-18.

41. Allaire $\mathbf{J}$, Maltais F, LeBlanc $\mathrm{P}$, et al. Lipofuscin accumulation in the vastus lateralis muscle in patients with chronic obstructive pulmonary disease. Muscle Nerve 2002; 25:383-9.

42. Couillard A, Maltais F, Saey D, et al. Exercise-induced quadriceps oxidative stress and peripheral muscle dysfunction in COPD patients. Am J Respir Crit Care Med 2003:167:1664-9.

43. Koechlin C, Couillard A, Cristol JP, et al. Does systemic inflammation trigger local exercise-induced oxidative stress in COPD? Eur Respir J 2004;23:538-44.

44. Vassilakopoulos T, Hussain SN. Ventilatory muscle activation and inflammation: cytokines, reactive oxygen species, and nitric oxide. J Appl Physiol 2007;102:1687-95.

\section{Lung alert}

\section{Role for Major Vault Protein in the innate immunity of respiratory epithelium}

Major Vault Protein (MVP) is thought to be important for innate immunity and is found in antigen-presenting cells and epithelia throughout the respiratory system. This study investigated the role of MVP in human respiratory epithelium, particularly in response to infection with Pseudomonas aeruginosa.

As $P$ aeruginosa initiates an innate immune response by forming lipid rafts on contact with lung epithelial cells, the authors analysed proteins recruited to lipid rafts and compared them with lipid rafts from uninfected cells. Using mass spectrometry, MVP was shown to be present in high concentrations within rafts. Immunofluorescence staining of $P$ aeruginosa infected cells confirmed co-localisation of bacteria with MVP.

MVP recruitment into lipid rafts by wild type-CF transmembrane conductance regulator (WTCFTR) gene-expressing cells was compared with cells expressing the $\triangle$ F508-CFTR gene. Cells expressing $\triangle$ F508-CFTR formed only $30 \%$ of the amount of MVP produced by WT-CFTR cells in the first $15 \mathrm{~min}$ of infection, although overall MVP expression was similar for both. Experimentally truncating the lipopolysaccharide outer core of $P$ aeruginosa impaired CFTR binding and eliminated MVP formation entirely. Lungs harvested from MVP knockout mice infected with $P$ aeruginosa showed 55\% less epithelial internalisation of the bacteria with a subsequent 3.5-fold increase in bacterial burden and increased mortality rate.

This paper supports a role for MVP in the innate immune response. Lack of MVP may increase susceptibility to infection. This work suggests that CFTR binding of bacterial lipopolysaccharide promotes the recruitment of MVP into lipid rafts which, in turn, enhances the epithelial internalisation of $P$ aeruginosa. The means by which MVP achieves has yet to be revealed and further studies are needed.

Kowalski MP, Dubouix-Bourandy A, Bajmoczi M, et al. Host resistance to lung infection mediated by major vault protein in epithelial cells. Science 2007;317:130-2

\section{Jenkins}

Correspondence to: D Jenkins, SHO Thoracic Medicine, Royal Free Hospital, London, UK; drjenkins@doctors.org.uk 